\title{
Considerations for Implementing Technology to Support Community Radio in Rural Communities
}

\author{
Laura Maye ${ }^{1,2}$, Sarah Robinson ${ }^{1}$, Nadia Pantidi ${ }^{1,3}$, Liana Ganea ${ }^{4}$, Oana Ganea ${ }^{4}$ \\ Conor Linehan ${ }^{1}$, John McCarthy ${ }^{1}$ \\ ${ }^{1}$ School of Applied Psychology, \\ ${ }^{2}$ School of Computer Science \\ and Information Technology \\ University College Cork, Ireland \\ \{laura.maye, sarah.robinson, \\ ${ }^{3}$ CMIC, School of Engineering \\ and Computer Science \\ Victoria University of Wellington, \\ New Zealand \\ nadia.pantidi@vuw.ac.nz \\ ${ }^{4}$ Active Watch, \\ Bucharest, Romania \\ \{liana, \\ oana\}@activewatch.ro
}

conor.linehan, john.mccarthy\}@ucc.ie

\begin{abstract}
Rural communities often lack platforms to support civic engagement and local deliberation. Community radio is intended to facilitate such functions, yet, radio technologies can be expensive and complex to use. To tackle this challenge, low-barrier radio technologies are becoming available. We argue that technology to support civic engagement and local deliberation are important, and design of such platforms must take into consideration specific community needs. We contribute by exploring the needs of three rural European communities. Findings indicate that communities are now distributed beyond place. Platforms for deliberation must include both hyper-local and geographically dispersed populations. Rural values of accountability, reliability and maintaining social harmony are important design considerations. Community radio platforms should support geographically distributed community connections, sharing of health and emergency information, preservation of heritage and act as a space for advocacy and civic action.
\end{abstract}

\section{Author Keywords}

Rural; community media; community radio.

\section{CSS Concepts}

- Human-centered computing Human computer interaction (HCI); Empirical studies in HCI

\section{INTRODUCTION}

Despite being home to 3 billion people, or $45 \%$ of the world's population, rural areas increasingly suffer from a decrease in media platforms dedicated to dialogue and

Permission to make digital or hard copies of all or part of this work for personal or classroom use is granted without fee provided that copies are not made or distributed for profit or commercial advantage and that copies bear this notice and the full citation on the first page. Copyrights for components of this work owned by others than the author(s) must be honored. Abstracting with credit is permitted. To copy otherwise, or republish, to post on servers or to redistribute to lists, requires prior specific permission and/or a fee. Request permissions from Permissions@acm.org. CHI '20, April 25-30, 2020, Honolulu, HI, USA.

(C) 2020 Copyright is held by the owner/author(s). Publication rights licensed to ACM. ACM 978-1-4503-6708-0/20/04...\$15.00 https://doi.org/10.1145/3313831.3376580 representation of their issues. Long-established rural newspapers are closing down, and local TV and radio stations are increasingly taken over by large media conglomerates [50]. There is a need for community-owned and controlled media in order to provide rural people with the means to communicate on local issues and participate in matters that are meaningful to them.

In many countries, community radio offers a localised, bottom-up alternative to mass media [44, 12, 13]. It is community owned, fosters information exchange that is locally sourced and verified, and can provide a space for local deliberation and participation in community decisions. Community radio can be valuable in rural areas, whose issues are typically under-represented in national media. However, radio stations are complex and expensive to set up and run; their cost and complexity mean they are often a far reach for many rural and remote communities.

New low power FM radio, internet and mobile phone technologies make it possible to build low cost, accessible platforms for community-level deliberation [10, 32, 38]. However, research on such platforms is limited, and primarily focuses on how the use of platforms impacts community dynamics $[32,38]$, or how radio can be technologically innovated and improved for scale [10]. We argue more attention ought to be placed on how such radio technologies could be designed to meet the unique needs and considerations of people in rural areas. Rural areas are culturally diverse; each has different qualities and resists general definition. As Hardy posits [20], rural communities are often overlooked by design and are positioned as "a problem to be designed away" rather than as a rich source of design inspiration. We argue the need to work with rural communities to understand the challenges in configuring radio technologies in light of the specific needs of those communities.

In this study, we conducted observations and interviews with three rural communities across Europe, that are in the process of setting up community radio stations. Data was collected in order to understand the behaviours, experiences, values 
and practices of the communities in relation to their communication, both within the community, and with the outside world. There was a focus on understanding the needs and concerns of the rural populations and how these can inform how new radio technologies could be deployed in response. Data was analysed thematically, resulting in a set of four descriptive themes: supporting community connections; revitalizing community; sharing information on natural emergencies and health; and reclaiming local decision-making and supporting advocacy. Analytic themes were also constructed from community data that indicate the importance of considering social harmony; accountability and reliability and volunteering in platform design for rural communities.

From our findings, we propose a set of considerations that we believe can be useful for HCI, community media professionals and amateurs setting up novel radio technologies in rural areas. These considerations include designing for community members near and afar, supporting community members in reimagining radio for community and local development, and promoting trust in using new technology for radio platforms. This is the first step in a large-scale EU participatory innovation project called Grassroots Radio [7] that aims to support six remote rural communities in setting up community radio stations using a novel radio technology called RootIO $[41,10]$. RootIO is a radio platform through which community members can broadcast using a basic phone, and aims to reduce the barriers (technical and social) toward setting up a community radio station. In Grassroots Radio, we adopt Participatory Action Research [23], where each rural community is actively involved in community radio setup, design and running.

\section{BACKGROUND}

\section{Defining Community}

In this paper, we are concerned with the needs of rural communities, and how these could be met by media technology. When we term "rural community", we refer to the idea of community that is traditionally bound by place. However, in our globalized world, the idea of place is often distributed, where people have a place attachment to the rural, yet physical habitation elsewhere. This notion of community is prevalent in rural areas, where its members are inherently distributed as a result of migration [20].

Due to this distributed nature of community, we draw on Anderson's [1] idea of imagined community. Community is imagined by people who perceive themselves to be part of the group wherever they may live. Technology can support this imagining through networked communities, in which the interweaving of technology and sociality lends itself to participation beyond geographic space $[1,35]$. Critically, in our definition, this imagining involves a spatial connection to a rural place. These are often mediated by the differing constructions of community boundaries. For example, in Irish island communities, there is a geographic place attachment or "islandness" that brings people together.
Within this, however, there are different levels of belonging and different needs. There are islanders who feel symbolically "from" the island. Additionally, there are those who live on the island but are not "from" the island, and those that visit in the summer and are have island kin [18]. These groups together form the "imagined community" of the island. This idea of community allows for multiple and sometimes dissenting voices and different ways of belonging. Belonging, however, is shared [25]. Further, these community boundaries in rural areas are important and navigated through values such as politeness [44, 29], privacy [21, 47] and trust [17], which imply potentially different design considerations, than those traditionally designed for urban subjectivities [22].

\section{Rural Communities, Civic Engagement and Technology}

How designers approach design and technology implementation in rural areas is a critical consideration [6]. HCI research has recently suggested an urban bias in design, with technology generally designed for urban settings with little consideration of rural needs [20]. Design is often based on modern (and urban) values of choice, productivity and control [20]. With over 3 billion people living in rural areas, and the current sustainability challenges of neoliberal urban growth centres, Hardy et al. [22] suggest a need for the recentring of design toward rural needs and values. In essence, they ask what do we need to do differently when we design for small rural communities rather than technology designed for scale in urban centres?

Considering the need for rural-focused design, research suggests that technological platforms for civic engagement could be beneficial for rural communities but must be tailored to rural needs, values and subjectivities [6]. Civic engagement is defined in HCI as "a collective or individual action designed to identify or address a particular public concern" [19]. While it can be social, political or goal orientated, civic engagement is generally not for profit [45]. Local platforms are probably needed more than ever, as contemporary neoliberal economic policies, negatively impact rural communities [22], contributing to a reduction in local media [49]. In many cases, globalization has led to outmigration of economically active groups to urban centres, declining and aging populations, with a parallel decrease in services. Policy decisions impacting rural communities are often made in urban centres without the input of those living locally.

Research has shown the need to shift toward a communityfocused approach, whereby rural community members are involved in making decisions that impact them [42]. Social media technologies have, to some extent, supported rural community deliberation, and have in some instances been favoured because of their ability to foster anonymization, indicative of the importance of privacy in rural areas [46]. Nonetheless, social media has been criticized by rural commentators for its design emphasis on urban subjectivities of scale $[20,21]$ and for the lack of resources to tailor such 
technologies with rural needs and subjectivities in mind. For rural areas, grappling with the impact of contemporary economic policies, we argue that technology to support civic engagement and deliberation on matters of local concern are important, and that design of such platforms must take into consideration specific community needs.

From a technological perspective, rural communities are further challenged in terms of access and availability to infrastructure. In an era of networked society [5], relational reach between communities is considered more important than geographic proximity for community development outcomes [3]. This is important when considering our view of distributed imagined networked communities which include in community geographically distributed members associated with a rural place. Yet there is a reliance on technology with strong connectivity to enable this, a requirement that is often unavailable or inconsistently provided in rural areas. There is a need for connectivity, with a corresponding infrastructure deficit that limits it. This design dilemma must be considered, in design of radio technology for local deliberation $[9,10]$. Despite this, rural communities have a history of appropriating technology to their contexts and needs [17] and as Hardy et al. [22] suggest have much to offer in terms of design insights, which we hope to apply to community radio technology design.

\section{Community Radio in Rural Areas}

According to AMARC Europe, the world association of community radio broadcasters [43], community radio is intended to support freedom of expression, is run by and for community members on mostly a voluntary basis, is nonprofit, and inclusive. Many community radio stations target participation of those within a community of place (i.e. associated with a particular geographical region) or a community of interest (i.e. with a specific hobby/interest) [11]. Radio, for community media purposes, has been argued as one that ought to support democratic decision making within communities [2, 13] and complement community members in advocating for change [15]. There is extensive literature on the impact of local radio in small EU rural contexts (e.g. [25, 24, 26, 12]). However, our work provides more recent viewpoints on the opportunities and challenges of community radio within EU in light of new low-cost radio technologies e.g. $[10,38]$. Further, our work emphasises the need to work with communities in a collaborative manner to understand their needs and values in the early stages of setting up local radio stations.

Much research on rural community radio has focused on three strands. First, research has looked at regulations and governmental policies and their impact on how community radio is supported and represented; e.g. Cibin et al. report on the regulatory policies that impact community radio setup in EU contexts [7]. The authors indicate there is no precedent for community radio in Romania, with regulations only providing for commercial radio, whereas in Ireland, there is a strong heritage of community radio. This strand of research explores the wider supportive context that enables or restricts sustainability of rural radio. In rural Africa, for instance, the wider economic context impacts the resources available to support community involvement in radio, with an overreliance on donor funds [28, 33]. However, this is mediated by the kind of technology deployed, with some new innovative platforms making radio more accessible to rural African communities [10]. Our work in contrast emphasises community needs and values as paramount, which ought to be taken into account in the implementation of new radio technologies in rural areas.

Another research strand has looked at the use of community radio, and its role in supporting community participation and development on a range of community identified issues including resource management, agricultural policy and maternal health $[28,27,31,30,16,50,36]$. In the European context, Day [11] highlights the goals of a rural community radio station in Ireland, and the strategies the station applies to sustain community development projects, which include active visibility in the community through outreach.

A third and more recent research strand is on the reimagining and redefinition of community radio through the integration of new emerging ICTs for rural areas developing world contexts. This research includes the design of tools such as the one adopted in our project (RootIO), which was originally designed to support rural communities in Uganda to discuss and advocate on local issues [10]. Another example is Avaaj Otalo, a radio platform intended to support deliberation amongst farmers in rural India [38]. This line of research primarily focuses on how the use of new radio platforms impacts political and community dynamics in developing regions. Moitra et al. [32] describe how a radio platform in rural India influenced the way in which communities mobilised on matters that affected them. Additionally, Talhouk et al. [47] present a case study on the use of Interactive Voice Response (IVR) radio for delivering refugee health shows in rural Lebanon. The authors explore how community dynamics were affected through its use, highlighting how the roles adopted in the radio show also impacted agency and privacy within those communities.

The value and impact of these new low-cost radio platforms to their respective communities are evident. Nonetheless, this strand of research is still nascent. Further work is needed to investigate values and needs before deployment of new radio technology. This study, to our knowledge, is the first to report on an array of rural communities setting up such radio stations within a European context.

\section{METHODOLOGY}

The data presented in this paper form part of an initial study, to explore the needs and concerns of people living in three rural communities engaged in an EU Horizon 2020 project called Grassroots Radio [7]. Grassroots Radio seeks to reimagine radio by integrating different types of old and new technology to lower the barriers for communities to have a radio platform. The project is operationalized in six rural 
communities on the periphery of Europe. The project employs Participatory Action Research (PAR) [23]. With PAR, each local community through gatekeeper organisations is a co-partner participating in design and decision making of community radio stations. As researchers, we document the process, engage with communities in situ, and support community participation. Here we focus on three rural areas in Europe in the months preceding the setting up of a radio station. There is a combination of insights gained through this pre-radio, and early days of radio platform operationalization in these rural communities.

This research completed in each region included field observations; desk research (including reports and statistics on each region), in-depth interviews with community members, and observations following initial radio broadcasts. Field observations took place between August 2018 - July 2019. There were multiple site visits during this period, with fieldwork lasting from 2 days to a week (over 6 months). The research also included informal conversations with members of each of the three communities. Following the observation, a researcher took notes of his or her encounter with community members. Interviews took place in each region at different times, as we detail in the description of each community. The interviews were conducted in the main language spoken in the region. Over six months, 25 people were interviewed across the three communities, lasting on average one hour. The main points from the interviews, along with interview excerpts, were summarised. Summaries of interviews were translated into English for analysis purposes, where relevant. We describe the rural communities below.

West Island is an island located off the coast of Ireland. There is a population of under 200 people living on the island all year round, with more people residing there during the summer period (between April and September). The island is connected by regular ferry to the mainland, although ferry services are reduced in the winter months. In total, we held ten in-depth interviews in West Island, which took place between March and June 2019.

East Village is a village in Romania, with a population of just over 800 residents who identify as Romanian $(91.84 \%)$, with a minority of Ukrainians (3.76\%). For $4.02 \%$ of the population, ethnicity is unknown. The village can only be accessed by boat. As the water freezes during the winter, it is often difficult to travel there during this period. The nearest city is $120 \mathrm{~km}$ away. Ten in-depth interviews in East Village occurred in November 2018.

South Village is another village in Romania. The population of the locality is over 2800 inhabitants, which had seen a decrease since the 2011 census when the population was 2,955 inhabitants. Most of the inhabitants declared themselves Romanians (96\%). The nearest urban centre is $18 \mathrm{kms}$ away which is often difficult to reach due to unreliable public transport. We held five in-depth interviews with community members of the village in December 2018.

Data was analysed thematically [4]. The resulting field notes, interviews and desk research data from all three regions were triangulated and grouped into themes by a team of three researchers. The first author derived the first collection of codes, which were revised by the two other researchers. Following this, the codes were grouped into themes and were shaped following another round of iteration. The study presented in this paper was approved by the first author's University ethics committee. All names, including the names of the rural areas, were replaced by pseudonyms. In the following sections, we will detail findings resulting from our observations and interviews with community members in these three rural regions. We highlight the similarities and differences in terms of community needs and challenges in those three rural areas and what this means for implementing community radio in those areas.

\section{FINDINGS}

\section{Supporting community connections}

Given the isolated nature of our three areas, a prominent need reported across all our participants was about supporting connections both between members living in the region and outside the geographical boundaries of place, with those who have left but still (feel they) belong to the imagined community.

\section{Strengthening Community Relationships and Maintaining Population}

All three regions are characterised by out-migration due to urbanisation, as well as lack of employment and education opportunities. Thus, the need to maintain, through strengthening existing relationships, and ideally increase the local population is one of the biggest needs across all three regions. In West Island, the dwindling population is a stark reality that saddens locals and puts the viability of the community and social services under threat. As one community member states in response to a question about his hopes and dreams for the island over the next ten years:

Yeah, well sustaining the population is a biggie. So like again, this year is a few more kids have been born, and that sort of... a bit of a buzz there (...) cause you know then that that will sustain the school. People literally do tot up the numbers. I think they were up to 25 last year, last couple of years and now we're down to 17 cos the kids get to 13 and they move over to the mainland school. (Local, West Island)

Similar issues of reduced population and service numbers were mentioned in interviews at the two villages in Romania, but also the need to strengthen relationships between existing residents was discussed. It was noted how despite being small communities, the personal relationships are not always as strong, both between the residents who have lived there all their lives and newcomers who are not symbolically identified as "from" the community and are at times challenged in how they are perceived and integrated. This is 
affecting the retention of people, attracting new residents and businesses:

It's unbelievable, it is a small community, and they do not get along with each other. They gossip. God, they're unbelievable. And what I've noticed, a funny thing, the man who works is not looked well upon. (...) They cannot stand outsiders to come and teach them. (...) It is difficult to develop here, as there is nothing available. There is not even a cinema. (Regular summer resident, East Village)

For those that are considered symbolically "from" the communities, there are sometimes differences in the values and pace of life of those that migrate from urban centres, as is implicit in the quote above. On West Island, for example, this was evident in the value of choice, with some locals having nostalgia for the limited ferry times to the mainland in the past, with others preferring more frequent services.

Considerations of the dynamics within rural communities, and the corresponding values of community boundaries between the different groups that make up community, where they begin and end, are important design considerations for community radio. Familiarity in small communities leads to considerations that must include privacy and sensitivity of these community boundaries in the design of any media platform. These are likely to be unique depending on the context but involve the need to consider who needs to be included for community radio design.

\section{Connecting with Diaspora and Family Living afar}

In addition to the in-migration, rural communities are now geographically distributed with links to community members in urban centres both nationally and in other countries. In South Village, $3.3 \%$ of people have a family member living abroad. While there are no statistics available for those from West island living abroad, community members have mentioned relations or close community members that live on the mainland of Ireland, mainland Europe, North and South America. Social inclusion of this diaspora in community deliberation is therefore increasingly important in maintaining the "imagined community" of rural and peripheral communities. As one resident stated:

Because so many people come to West Island when they don't actually live there so having that platform available, if it was online or something like that... could be really interesting... And eh...I think definitely it would have a listenership... I think maybe for island people themselves I'm not sure, it will be as useful, as it will be for people who aren't living on the island. Because I don't know... I mean if people already know the news... I don't know whether they are going to be listening to it again... but I know if I was in the city, I'd definitely tune in. (West Island resident, living away from the island)

There are also seasonal influxes in all communities, with many migrants leaving for the winter months and returning in summer. Winter months can mean a reduction in services in areas and in spaces for social engagement. Finding ways to maintain these connections are important, particularly in East Village and West Island where friends and family members move away remain psychologically part of the community. The residents of East village are disconnected during the winter months, as the water connecting to the village sometimes freezes. As the village does not have a high school, many children move to the nearest city to continue their education. The first need of these rural communities is finding a way to maintain distributed community connections throughout the seasons, in a way that includes the voices of those that are psychologically present in community, while physically absent. Finding ways to sustain community viability is one of the core needs, that radio platforms could support, through creating spaces for civic engagement and deliberation on this and related issues, as well as including the distributed nature of community.

\section{Revitalising Community}

A further need, as a result of depopulation and migration challenges described above, was the need to revitalise the local community. Residents in all three areas discussed the need to keep traditions alive, to create opportunities for joint activities between community members, to support education, and create a space for civic engagement.

\section{Preserving Traditions}

Participants discussed how they have witnessed the decline or extinction of local traditions. Traditions such as the social cooking of food or traditional dancing are facing extinction. For example, in South village, cooking bread on a furnace, despite being a local tradition for centuries, is no longer widely practiced. Other, once popular, activities in the village have also seen their popularity dwindling, including local fairs:

We have fairs, but they have lost their charm. (...) Services are no longer to the liking of people (...) The musicians are no longer coming..." (Local, South Village)

For West Island, the steady decline in population has placed the distinctive way of island life under threat. Finding a way to capture the stories of islanders and to preserve the oral heritage was of high significance to the local community. Radio technology could enable them to document, disseminate these stories, and preserve them for future generations. This is linked to the need to sustain community viability as this extract from our field notes suggests:

Peter talked about sustaining the population and the fact that the island population has decreased and continues to decrease - for him it is about sustaining the population, through learning about why people left in the past. He talked about certain families that had to leave and move to the city or emigrate - it would be interesting to ask them why they had left in order to understand what would have made it easier for them to stay. He said that many of the older people tell the young people to get off the island as there are no opportunities here - so it's important to also capture the 
positive side of things. What were the practices that people enjoyed. (field notes, West Island)

The need to have tools to enable community members to record their traditions and share them with others to keep them alive was evident. Members of West Island noted that radio could be a good platform for sharing recorded oral histories with others. Particularly in the case of West Island, we also see the need to record histories of former members living elsewhere to share their stories, thus strengthening the need to maintain connections with other places.

\section{Creating space for social activities}

As residents and services diminish, the remaining inhabitants of those isolated regions expressed their need to have more opportunities for social community activities both to revitalize relationships within the community and to attract new populations. As a member of West Island says:

It's difficult. There are no events as such that I know of, that I get involved in, apart from, in the summer, you've got a festival, swim and sailing events and all that kind of stuff goes on, which is nice. There's nothing in particular. It's just a small community. You just live and you get on with life and that's it. (Local, West Island)

In East Village, the centre for social activities, particularly for men is the local pub, while women primarily socialise at home. West Island and South Village have some social activities; however, these activities tend to take place when there are collective interest and enough people. Residents of West Island noted that social events, such as language classes, dynamically change depending on who is living on the Island. One interviewee reported using social media tools to connect with people in other regions as a way to strengthen social relationships with people of similar interests.

During our fieldwork, it also became evident that, across all three communities, there was a large aging population so providing social avenues to support and engage older adults living in the community was a priority for the locals. In East Village, where the need to support older people in socializing was particularly highlighted, it was suggested that community radio can be seen to support this well. This was indicated in West Island. To sustain rural activities, building a critical mass (i.e. enough people) who have interest in keeping communities alive is what determines their continuity. Similar to what we saw with community traditions, without this critical mass, those activities tend to cease. Connections with people in other places can be useful to keep activities alive and maintain a diversity of activity.

\section{Sharing information for natural emergencies and health issues}

Currently, communities use social media, word of mouth and printed media to access local news. However, in all regions, the remote nature also translated to challenges when dealing with and responding to states of emergency. As a result, a key need that emerged when considering technological platforms and tools was sharing information during emergencies and obtaining specialised advice.

Participants across three regions spoke about various ways that their community is challenged when natural phenomena such as storms or fires happen. Community members in East and South Village felt that radio could be a useful alternative for information sharing, particularly during storms when different communication systems could fail, as indicated above. Equally, residents in West Island noted that although fire emergencies do not occur regularly, when they do happen, it is important to be able to respond to such events promptly, inform each other and initiate collective action. There is a need to support sharing and coordination of spontaneous, yet important, community information in time of emergencies especially as locals may reside at significant distance from each other or may not be able to evacuate on their own. In all regions, it was deemed important to share information widely so other community members and emergency personnel can respond and take action.

Medical emergencies pose a significant challenge on the communities studied. Critical incidents require calling a helicopter as any other form of transport would be very timeconsuming. Even when the incident is not urgent, having access to specialized medical information can be difficult yet needed. West Island is host to one nurse who is available to respond to everyday health concerns and the only one with the authority to call the helicopter to collect someone who may be sick. In East Village, a general doctor comes to visit the community twice a week for several hours; there is also a medical assistant and dentist available. South Village has a bigger population and as a result has a permanent health centre with two general practitioners (GPs) and two nurses, as well as two pharmacies. Additionally, the GPs visit locals who are unable to travel to the health centre. Nonetheless, health services remain limited even in South Village.

There are limited health options for people with chronic conditions to obtain health information in the area; limited services for people who need specialised services (e.g. paediatrics or gynaecology); and lack of sex education and drug education for the youth. Information and consultation on such health issues albeit of not critical nature, was discussed as very important and with the potential to impact people's daily lives. Having a community radio platform was seen as a means to address the current gaps in specialized health information that can be tailored to the specific needs of each community and broadcasted in an appropriate manner to those who require it and may be excluded due to distance from the medical establishments or lack of access to other information sources (e.g. online resources).

\section{Reclaiming local decision-making and supporting advocacy}

Another key need expressed by our participants involved having a way to advocate and have their voices heard with regards to local matters. As mentioned already, all three rural communities are located in isolated geographic peripheries. 
This isolation presents a further challenge for community members across all three areas, in that much of the decision making that affects the provision of services and infrastructure is made in urban centres, such as the country capital or the closest city, by people not familiar with the day to day issues of the localities. For example, in East and South village, one of the main sources of civic information and deliberation is the town hall. Participants noted that greater dialogue between the town hall and the community members is needed. This type of dialogue is also a consideration for West Island, where some community members discussed the need for greater transparency in community decisions and feedback at the hyper-local level, and an improvement of communication between the island and the local administration on the mainland of Ireland.

Further, community members across the three regions expressed their discontent for not being heard about national and transnational policies that affect them, especially as the effects can be very different compared to urban centres and the peripheries. For example, on West Island there was a motion to remove the nurse from the island, which has for now been blocked. This motion was based on a national decision about the provision of public health, which was based on numbers of population, and did not take into account the specific health needs related to the geographic isolation of an island. Similarly, in East Village, locals talked about the impact of national polities on fishing, one of the two main sources of income, and environmental management, by policies designed by authorities with insufficient consultation of the locals:

Before the '90s the river basin was populated with fish. There was a lot of fishing going on, but there was also a lot of fish that survived. Well, after the '90s, nobody is populating with fish. And as such, everyone catches fish, and no one puts some back. And at some point, as it was in the summer, many locals were looking for fish, and nobody was catching. It's a laugh, but it's a sad truth. And no action is taken. (Resident, East Village).

In West Island, the positioning of islanders as numbers for services is also evident in interviews and illustrates that decisions that impact rural communities are often based on values related to population density, which become internalised and create anxiety about the community's sustainability. This was the case in the decision to remove the nurse discussed in above. Below, an islander talks about how decisions are made by the central government based on population density, rather than community needs.

Interviewer: And when there was a risk about that job going? Did the community come together?

Resident: Well I think everyone was trying to support her, trying to support her as much as they could... But like, you're just a number up there in Dublin [central government]. Same with the post office, if they don't want... if they decide. That's it. (Resident, West Island).
For residents of all three communities, there seems to be little to no community-focused platforms for people to share their voice on local issues and for their voices to be heard on matters of civic engagement. At present, the locals discussed how they share their voice on such issues on cause-specific groups on social media and whenever possible on national radio. However, these platforms are mediated by outsiders who are not deeply aware of local issues.

Our findings also highlighted the need for rural communities to foster connections with people and organisations in other geographic communities and to deliberate on issues that commonly impact them. In West Island, this can translate to building links with other Irish islands, to act on challenges that commonly impact them, and to advocate for policies that can sustain island communities. Technology, and particularly radio, can offer ways for islanders to connect with others and create dialogues on such issues. Finding ways to sustain community viability is one of the core civic engagement themes that emerged. It is important to consider how radio could be implemented to support communities in participating in such dialogues.

\section{Practical concerns around community radio}

Radio as a media platform was familiar to our participants and the majority were very positive towards the idea of community radio. Still, when considering the practicalities of setting up a radio station, themselves as producers and radio as a community platform that they will have a direct say and participation in its content and decision making, a number of concerns arose primarily around issues of intracommunity relationships, accountability and volunteering.

\section{Maintaining social harmony within rural communities}

Several community members across all areas shared concerns regarding the use of radio as a community sharing platform and the effect their participation in it could have on existing and emerging relationships in the community. In East Village the locals were concerned that implementing radio may amplify existing tensions in the area, which are described under the theme Strengthening community relationships and maintaining population (above). In West island, the geographic implications of "islandness" mean that people rely on reciprocity for survival, anything that could upset the social harmony of the island and the norm of reciprocity is avoided. As a result, islanders are fearful of discussing anything that could be considered offensive on the radio or being perceived in a particular light that could have repercussions for their standing in the community. This will need to be considered in the design of radio content and it could be important that trust is built in terms of what radio can do to support and strengthen existing relationships.

\section{Accountability and Reliability}

Who is responsible if things go wrong? To what extent can the setup of the radio technology be held accountable/is trustworthy? These were the main concerns that community members had about setting up and operationalizing of a community radio platform in their respective communities. 
In each rural area, community members, especially the ones considering becoming more directly involved in establishing radio stations, voiced concerns about what would happen if anything were to go wrong, such as, someone expressing themselves inappropriately on air, and talked about feeling accountable to their communities if problems arise. Although, by definition, community radio programs are not expected to be produced by professional broadcasters, participants felt that it was their responsibility to do a 'professional' job, ensuring their diction was clear and broadcast information was accurate, as illustrated by a community member in South Village:

Even me I would love it, but this fear that you do not know what to do, you do not know where to start... at the radio one must to have a diction, you have to talk correctly on the radio, you have to know on the radio. If a person asks you a question and you do not know, what are you doing? (Local, South Village)

The technical reliability of the radio was a source of concern and whether it will be able to perform professionally. In line with previous concerns and expectations for professionalism in community media, in West Island, participants explained how they need to be able to trust that the system will run in any weather condition and work on days of broadcast. A community member on West Island highlighted:

There is the sense of being involved in an amateur drama production, and when the lights go up everything must work (Local, West Island)

This suggests a performative element to the radio, and the importance of technology that works and is reliable. Having a reliable signal transmission and broadcast were discussed as particularly important in the early stages of station setup to ensure community support for the radio. Without this, community members felt they would lose interest in the community radio. Reliability was also regarded as critical to the community's reputation outwardly to other communities, the rest of the country, or even further to the diaspora.

These concerns around accountability and reliability became even more prominent as participants familiarized themselves with each country's legal framework around public (radio) broadcasts which indicated clear legal repercussions (e.g. fines or other penalties) for cases inappropriate public speech; and implications for continued ability to have a licence for radio due to interruptions of the broadcasting for longer periods of time.

For these community members, credibility within the community appears to be at stake, if the technology for radio fails. On an individual level, we see there is fear in how misrepresentation on the radio may lead to change in community dynamics and the image and reputation in the community. On a community level, we also see how the technology itself forms part of the community's image inwards and outwards and it is needed to see working to be a useful community tool. Geographically remote communities are notable for their self-reliance and the importance of sustainability given their isolation [18]. This is a significant design consideration for radio and any other technical platform in these communities toward how trust of the technology - and in particular at early prototyping stages must be ensured and maintained in rural communities.

\section{Volunteering}

Community radio by definition requires community members to be active participants in the running or programming of the station. This ensures that the community (or at least a segment of it) self-identifies with the station, that content is relevant and interesting to the community and keeps it alive financially. Community radios especially in their nascent stages depend on volunteers from the community to sustain them across all aspects of their operation: creating and presenting programmes, researching news, doing technical support, finding sponsors etc. This considerable dependence on volunteering for the community radio to operate was found to be a significant concern across all three studied regions albeit in various manifestations.

For East and South Villages, volunteering is not commonly seen as part of everyday life and culture. As a local resident of the East Village shared, volunteering is often associated with the country's political past and therefore seen as outdated:

Volunteering's harder today, obsolete ideas that patriotic work was done during communism (Local, East Village)

However, between the two villages, the responses towards volunteering for a local community radio varied. In the East Village, willingness to volunteer was moderated by a broader skepticism around radio. In cases where the idea was praised, it was dependent on the value of the radio content to the specifics of the community life:

It has to be focused on the specifics of the village more. Or to say what is done, what is happening, especially in the summer. (...). From the village life. General information can be found from any radio (Local, East village)

In South Village, there was a higher interest from the locality to become involved in the radio. The community-focused aspect of the radio was one of the things that drove some community members toward seeing the value it could add to the community and praising its implementation. As one local puts it, community radio provides:

The opportunity to talk freely, and not be seen like on TV, and they would just say their opinion, I think we would learn a lot... interesting things, news even for us" (Local, South Village)

In contrast to the East and South Village, on West Island, volunteering is a common practice. However, the declining population has made volunteering challenging in recent years, especially since many volunteering activities are led by same (key) people in the region, resulting in fatigue: 
If you volunteer here, you might be still doing it in 40 years time (Local, West island).

Thus, while many people in the island are enthusiastic about having a local community radio, the challenge is finding people to volunteer. Older members of the community, who are practiced in volunteering and have available free time, feel this should primarily be a platform for the youth to build skills and roots with the locality. They are keen to support the initiative but need to know they can pass the torch to the younger generations to carry.

As argued by others, it can be challenging in areas with smaller populations to get a critical mass of volunteers needed to sustain community radio [11]. Declining populations, such as in West Island, have an impact on community activity. We argue that it may be important to facilitate and enable volunteering from geographically distributed community members in rural community media. However, for community radio to be sustainable, we agree with Day [11], who suggests volunteers should ideally have a stake in that community and believe radio can support it.

\section{DISCUSSION}

In all rural communities presented, our findings highlight their needs towards maintaining current and attracting new populations, revitalizing local traditions and social activities, encouraging participation of all associated members and bottom-up deliberation to address local issues. The importance of technological solutions to support the dissemination of information for everyday and emergency situations within and outside of the region is also evident. In the following sections, we will provide considerations to community media professionals, HCI designers and communities designing, implementing and setting up radio technologies to support community participation in community radio platforms in rural areas. With differences between rural communities, we concur with Hardy et al. [22] and Chamberlain and Crabtree [6] that unique rural needs should remain a strong source for design inspiration.

\section{Community Radio for geographically distributed communities}

Opening connections outside of the region in order to support sustainability was a strong need expressed by participants in all three regions. Finding ways for distributed community members to engage and participate in community decisions and community life then is important. And secondly, in the case of West Island there was a need to increase relational reach [3] and critical mass by networking with other islands on issues of common concern. This finding is particularly significant from a design perspective as it disputes existing literature and the tradition of community radio being all about local topics and local range. As Mynatt et al. have found, "shifts in membership population often require reconfiguration of techno-social conventions" [34, p:216]. Essentially, the design suggestion here is to extend the reach of the radio platform outside the hyperlocal, to provide a community radio platform where these "locals" that have a local interest but are not physically present are included and allowed to participate. In this respect, considering what range is too wide to be considered community [11] needs to be negotiated between designers and each rural region, to establish from the perspective of the locals, what broadcasting range includes relevant community members, and what radio technologies can support that span.

Community radio tends to be designed for discrete geographic regions, rather than for distributed imagined communities commonly associated with rural areas. Some new radio technologies designed to reduce complexity of participating in local media apply FM broadcasting [10]. However, as the FM broadcasting range is bound to a geographical place (which are, as Day highlights [11], heavily regulated), it may not be appropriate for including the distributed community members living near and afar that associate as rural. Therefore, re-imagining radio for this demographic appears to be an important design consideration that has been overlooked. In West Island and the two Romanian villages, this means including community members living in South and North America and other parts of mainland Europe, as well as community members in national urban centres or surrounding rural areas. A combination of FM and digital broadcasting may be beneficial to capture the diverse needs of those that remain and may have low connectivity [42] and those that are in other digitally connected areas.

\section{Re-imagining radio to meet community needs}

As Day [11] defends, there needs to be a mindset from the community that radio will have a positive impact and can support participation in community initiatives to be a useful tool. Particularly in Ireland, literature highlights that barriers to community participation are often related to the perception on what radio is, rather than its design as a tool. Gaynor and O'Brien [15] document how the erosion of Irish civil society due to neoliberalism has led to the blurring of community and State boundaries, in which community development organisations involved in community radio have become service providers, rather than community mobilisers.

As a result, radio is seen as a service, where key media representatives provide information, rather than as a tool for supporting community deliberation and participation. They believe, the radical social change potential of community radio is therefore missed. What this suggests is that there is a need to conduct activities that support communities in discovering the potential of a radio platform as a tool for radical social change and transformation. HCI has a long tradition in community engagement activities (especially in the context of (re)imagining technology) as well as a wide range of methodologies and tools to support those; from envisioning [39, 40], design fiction $[37,48,51]$ to participatory and experienced centred design $[8,14]$. Thus, as HCI researchers and practitioners, we are well situated and for that responsibility, to support communities in 
understanding and appropriating the potential of media platforms at the local level in social change processes.

\section{Building trust around new radio technology and tools}

Radio can, and has been, used as a tool by many communities as a means to promote inclusion of community members in discussing everyday matters, as well as a tool for supporting community deliberation on topics such as agriculture, healthcare, education, and policy challenges. However, as illustrated in our findings, discussing such topics, albeit trivial, may be perceived as a challenge to the intracommunity relations and dynamics of small rural communities. It was clear that community members need to feel safe and that involves trust that participating in the radio will not lead to unwanted or undesirable effects in terms of community relationships.

It would appear that the social boundaries of talk in small rural communities and very much linked to social action and there can be repercussions that community perceive could have lasting consequences. While it may be that only through extended use of the radio this is achieved, it is still worth considering from an HCI perspective whether tools or features can be introduced in the traditional radio platform to build incremental trust, confidence and prevent unwanted exposure within such small and intimate community settings. Considering Sengers [44], McCarthy \& Wright [29], Talhouk et al. [47] and others suggestions that in rural communities values such as politeness, sensitivity to community boundaries and privacy are important considerations that any media platform should consider.

\section{Considerations toward advocacy and a platform for sharing local voice}

Technology, policies, and services are traditionally designed to scale and are often in conflict of needs of those in rural regions. We see this issue in East Village, where transnational fishing policies have impacted local fishing practices, and in West Island where national policies on health and other social services and transport have an impact on the lives of locals. Hardy et al. [22] suggest the need to design for individual rural needs. One of the biggest challenges for rural regions (and particularly the ones identified in this paper) is the remote nature. Radio could be seen as a tool that enables people in rural regions to have a voice on issues that are pertinent to the locality, thus enabling them to initiate design from the bottom-up. This is another example for where supporting connections outside of the region are important, as many policy makers, professionals and other individuals are often not located in rural areas. Communities are the experts of their day-to-day challenges, while domain experts such as officials, healthcare professionals, etc. are experts of their field. Through providing a means of opening up and connecting these groups in efficient ways, radio could prove to be a useful tool for community advocacy and collective action.

Radio can provide opportunities for community members to voice why and how certain decisions or policies affect a locality, providing a base for officials to gain better understandings of the collective needs of people living in rural areas, and a space for dialogue between local communities and officials that serve them. However, it is important community voices can also linked with commonly used information platforms used by officials, to be effective for advocacy purposes. While it remains an open question as to how this may be done, it could be that voices can be linked to social media sites or mailing accounts of officials. This repackaging of content could be listened to asynchronously, as officials may not be available to listen to radio content in real time. However, as voice is distinct, extending boundaries of voice may impact identity [35] which is important to maintain for small rural communities.

\section{LIMITATIONS}

There are some limitations to this work. Firstly, as this study was designed to glean in-depth information on the needs and concerns of people living in three rural communities, it targeted a small group of people within each region, thus generalization is difficult. However, our findings capture a holistic perspective on why community members need to connect for deliberation and what radio technologies can offer from a European rural perspective. Furthermore, our study focuses on the perspective of community members before integrating new radio technologies in rural areas in Europe. This supported us in identifying the needs and concerns of mobilizing the communities in using the radio. However, we believe future work could explore how those viewpoints change over time and what implications this has on the "imagined" communities constructed by those associated with the rural.

\section{CONCLUSION}

In this paper, we detailed the needs and concerns of people living in three rural communities in Europe to inform the design and integration of new low-cost radio technologies. Our research takes the viewpoint that rural communities include people who have a spatial connection to a rural place, whereby boundaries of belonging are socially constructed. Taking this stance of community, our findings revealed the need to support community connections both near and afar and to revitalise traditions and social activity. However, there are practical concerns around community radio integration that ought to be considered, including accountability and how volunteering is perceived. We presented design considerations for setting up new radio technologies in rural areas that include people both inside and outside of the geographical place, that support rural community members in re-imagining what radio may provide locally and gaining trust in new radio technologies.

\section{ACKNOWLEDGMENTS}

We thank the community members involved in this project for their participation and contributions to this work. This study was supported by Grassroots Radio project (20182020). This project received funding from the European Union's Horizon 2020 Research and Innovation Programme under Grant Agreement No 780890. 


\section{REFERENCES}

[1] Benedict Anderson. 2006. Imagined communities: Reflections on the origin and spread of nationalism. Verso books.

[2] E. W. R. Barlow. 2008. Community Radio in the US: The Struggle for a Democratic Medium. In Radio: Critical Concepts in Media and Cultural Studies, Vol. III. 43.

[3] Bettina B. Bock. 2016. Rural marginalisation and the role of social innovation; a turn towards nexogenous development and rural reconnection. Sociologia Ruralis 56, 4 (2016), 552-573.

[4] Virginia Braun, Victoria Clarke, and Gareth Terry. 2014. Thematic analysis. Qual Res Clin Health Psychol 24 (2014), 95-114.

[5] Manuel Castells. 2011. The rise of the network society. Vol. 12. John Wiley \& Sons.

[6] Alan Chamberlain and Andy Crabtree. 2013. Innovation in the wild: ethnography, rurality and participation. In The 3rd Participatory Innovation Conference, PIN-C. Lappeenranta University of Technology.

[7] Roberto Cibin, Maurizio Teli, and Sarah Robinson. 2019. Institutioning and Community Radio. A Comparative Perspective. In Proceedings of the 9th International Conference on Communities \& Technologies - Transforming Communities (C\&T '19). ACM, New York, NY, USA, 143-154. http://dx.doi.org/10.1145/3328320.3328392

[8] Rachel Clarke, Clara Crivellaro, Danilo Di Mascio, and Peter Wright. 2016. Re-configuring participatory media for citizen elders in urban planning. In Proceedings of the 3rd Conference on Media Architecture Biennale. ACM, 12.

[9] Rute Correia, Jorge Vieira, and Manuela Aparicio. 2019. Community radio stations sustainability model: An open-source solution. Radio Journal: International Studies in Broadcast \& Audio Media 17, 1 (2019), 2945.

[10] Chris Csikkszentmihàlyi and Jude Mukundane. 2016. RootIO: ICT + telephony for grassroots radio. In 2016 IST-Africa Week Conference. 1-13. http://dx.doi.org/10.1109/ISTAFRICA.2016.7530700

[11] Rosemary Day. 2009. Community radio in Ireland: Participation and multiflows of communication. Hampton Press.

[12] Jan Drijvers. 1992. Community broadcasting: a manifesto for the media policy of small European countries. Media, Culture and Society 14, 2 (1992), 193-201.

[13] Christina Dunbar-Hester. 2014. Low Power to the People: Pirates, Protest, and Politics in FM Radio Activism. MIT Press.
[14] Sarah Foley, Daniel Welsh, Nadia Pantidi, Kellie Morrissey, Tom Nappey, and John McCarthy. 2019. Printer Pals: Experience-Centered Design to Support Agency for People with Dementia. In Proceedings of the 2019 CHI Conference on Human Factors in Computing Systems. ACM, New York, NY, USA, 404.

[15] Niamh Gaynor and Anne O'Brien. 2017. Community radio, democratic participation and the public sphere. Irish Journal of Sociology 25, 1 (2017), 29-47.

[16] Joost Gieling, Lotte Vermeij, and Tialda Haartsen. 2017. Beyond the local-newcomer divide: Village attachment in the era of mobilities. Journal of Rural Studies 55 (Oct.2017), 237-247. http://dx.doi.org/10.1016/j.jrurstud.2017.08.015

[17] Eric Gilbert, Karrie Karahalios, and Christian Sandvig. 2008. The network in the garden: an empirical analysis of social media in rural life. In Proceedings of the SIGCHI Conference on Human Factors in Computing Systems. ACM, 1603-1612.

[18] Peter Gill. 1994. Island psyche: Fieldnotes from an Irish island. The Irish Journal of Psychology 15, 2-3 (1994), 276-287.

[19] Mike Harding, Bran Knowles, Nigel Davies, and Mark Rouncefield. 2015. HCI, civic engagement \& trust. In Proceedings of the 33rd Annual ACM Conference on Human Factors in Computing Systems. ACM, 28332842. https://doi.org/10.1145/2702123.2702255

[20] Jean Hardy. 2019. How the Design of Social Technology Fails Rural America. In Companion Publication of the 2019 on Designing Interactive Systems Conference 2019 Companion. ACM, 189-193. https://doi.org/10.1145/3301019.3323906

[21] Jean Hardy and Silvia Lindtner. 2017. Constructing a desiring user: Discourse, rurality, and design in location-based social networks. In Proceedings of the 2017 ACM Conference on Computer Supported Cooperative Work and Social Computing. ACM, 1325. https://doi.org/10.1145/2998181.2998347

[22] Jean Hardy, Chanda Phelan, Morgan Vigil-Hayes, Norman Makoto Su, Susan Wyche, and Phoebe Sengers. 2019. Designing from the Rural. Interactions 26, 4 (June 2019), 37-41. http://dx.doi.org/10.1145/3328487

[23] Gregory N. Hearn, Jo A. Tacchi, Marcus Foth, and June Lennie. 2009. Action research and new media: Concepts, methods and cases. Hampton Press.

[24] Nick Jankowski, Ole Prehn, and J. G. Stappers. 1992. The people's voice: Local radio and television in Europe. Vol. 6. J. Libbey.

[25] Per Jauert. 1997. Local Radio in Western Europe Conflicts Between the Cultures of Center and Periphery. The Nordic Review 2, 1 (1997), 93-106. 
[26] Marcel Machill. 1996. The French Radio Landscape: The Impact of Radio Policy in an Area Defined by the Antagonistic Forces of Commercialization and Cultural Protection. European Journal of Communication 11, 3 (Sept. 1996), 393-415.

http://dx.doi.org/10.1177/0267323196011003006

[27] Linje Manyozo. 2005. Rural radio and the promotion of people-centred development in Africa: Radio listening clubs and community development in Malawi. A paper presented at the Codesria 11 General Assembly. Retrieved May 5, 2009.

[28] Linje Manyozo. 2009. Mobilizing rural and community radio in Africa. Ecquid novi 30, 1 (2009), 1-23.

[29] John McCarthy and Peter Wright. 2017. Commentary: Making interactivity meaningful for contemporary HCI. Human-Computer Interaction 32, 3 (2017), 148152.

[30] Blythe McKay. 2009. Using community radio in Ghana to facilitate community participation in natural resource management. ECQUID NOVI 30, 1 (2009), 73-93.

[31] Eronini R. Megwa. 2007. Bridging the digital divide: Community radio's potential for extending information and communication technology benefits to poor rural communities in South Africa. The Howard Journal of Communications 18, 4 (2007), 335-352.

[32] Aparna Moitra, Vishnupriya Das, Gram Vaani, Archna Kumar, and Aaditeshwar Seth. 2016. Design Lessons from Creating a Mobile-based Community Media Platform in Rural India. In Proceedings of the Eighth International Conference on Information and Communication Technologies and Development (ICTD '16). ACM, New York, USA, 14:1-14:11. http://dx.doi.org/10.1145/2909609.2909670

[33] Mary Myers. 2008. Radio and development in Africa: A concept paper. Technical Report. https://idl-bnc-idrc.dspacedirect.org/bitstream/ handle/10625/41180/129100.pdf

[34] Elizabeth D. Mynatt, Annette Adler, Mizuko Ito, and Vicki L. O’Day. 1997. Design for network communities. In Proceedings of the ACM SIGCHI Conference on Human factors in computing systems. ACM, 210-217.

[35] Elizabeth D. Mynatt, Vicki L. O’Day, Annette Adler, and Mizuko Ito. 1998. Network Communities: Something Old, Something New, Something Borrowed... Computer Supported Cooperative Work 7 (1998), 123-156. https://link.springer.com/article/10.1023/A:100868820 5872

[36] Anthony A. Olorunnisola. 2009. Media and communications industries in Nigeria: Impacts of neoliberal reforms between 1999 and 2007. Edwin Mellen Press.

[37] Daniel Pargman, Elina Eriksson, Mattias Höjer, Ulrika Gunnarsson Östling, and Luciane Aguiar Borges. 2017. The (un) sustainability of imagined future information societies. In Proceedings of the 2017 CHI Conference on Human Factors in Computing Systems. ACM, 773785. https://doi.org/10.1145/3025453.3025858

[38] Neil Patel, Deepti Chittamuru, Anupam Jain, Paresh Dave, and Tapan S. Parikh. 2010. Avaaj otalo: a field study of an interactive voice forum for small farmers in rural India. In Proceedings of the SIGCHI Conference on Human Factors in Computing Systems. ACM, New York, USA, 733-742.

https://doi.org/10.1145/1753326.1753434

[39] Stuart Reeves. 2013. Building the Future with Envisioning. Interactions January + February, 26.

[40] Tom A. Rodden, Joel E. Fischer, Nadia Pantidi, Khaled Bachour, and Stuart Moran. 2013. At Home with Agents: Exploring Attitudes Towards Future Smart Energy Infrastructures. In Proceedings of the SIGCHI Conference on Human Factors in Computing Systems (CHI'13). ACM, New York, USA, 1173-1182. http://dx.doi.org/10.1145/2470654.2466152

[41] RootIO. 2019. RootIO Radio - a technology platorm for low cost, hyperlocal community radio stations. http://rootio.org

[42] Koen Salemink, Dirk Strijker, and Gary Bosworth. 2017. Rural development in the digital age: A systematic literature review on unequal ICT availability, adoption and use in rural areas. Journal of Rural Studies 54 (Aug. 2017), 360-371. http://dx.doi.org/10.1016/j.jrurstud.2015.09.001

[43] Sally. 2013. The Community Radio Charter for Europe. (May 2013). http://www.amarceurope.eu/thecommunity-radio-charter-for-europe/

[44] Phoebe Sengers. 2011. What I learned on Change Islands: reflections on IT and pace of life. Interactions 18, 2 (2011), 40-48.

[45] Sally Shortall. 2008. Are rural development programmes socially inclusive? Social inclusion, civic engagement, participation, and social capital: Exploring the differences. Journal of Rural Studies 24, 4 (2008), 450-457.

[46] Michael J. Stern and Alison E. Adams. 2010. Do Rural Residents Really Use the Internet to Build Social Capital? An Empirical Investigation. American Behavioral Scientist 53, 9 (May 2010), 1389-1422. http://dx.doi.org/10.1177/0002764210361692

[47] Reem Talhouk, Tom Bartindale, Kyle Montague, Sandra Mesmar, Chaza Akik, A. Ghassani, M. Najem, H. Ghattas, Patrick Olivier, and Madeline Balaam. 2017. Implications of synchronous IVR radio on Syrian 
refugee health and community dynamics. In Proceedings of the 8th International Conference on Communities and Technologies. ACM, 193-202.

[48] Joshua Tanenbaum, Karen Tanenbaum, and Ron Wakkary. 2012. Design Fictions. In Proceedings of the Sixth International Conference on Tangible, Embedded and Embodied Interaction (TEI '12). ACM, New York, USA, 347-350.

http://dx.doi.org/10.1145/2148131.2148214

[49] Transparency. 2016. Corruption Perceptions Index 2016 - Transparency International. (2016). https:/www.transparency.org/news/feature/corruption perceptions_index_2016.

[50] Catharina Cornelia Maria Van Vuuren. 2004. Community participation in Australian Community Broadcasting: A comparative study of rural, regional and remote radio. Griffith University.

[51] Richmond Y. Wong and Deirdre K. Mulligan. 2016. When a product is still fictional: anticipating and speculating futures through concept videos. In Proceedings of the 2016 ACM Conference on Designing Interactive Systems. ACM, 121-133. https://doi.org/10.1145/2901790.2901801 